\title{
Heritability of Lip Print Patterns among North Indian Populations
}

\author{
Yogesh Vats ${ }^{1}$, Jasmine Kaur Dhall ${ }^{2 *}$ and A. K. Kapoor ${ }^{3}$
}

${ }^{1}$ Department of Anthropology, University of Delhi, India

${ }^{2}$ UGC-JRF, Anthropology Department, University of Delhi, India

${ }^{3}$ Anthropology Department, University of Delhi. India

\begin{abstract}
Various physical and trace evidences allow a range of possibilities to carry out forensic investigations. Fingerprints, DNA profiling, Forensic anthropology are commonly employed in personnel identification, mass disasters, inclusion and exclusion. In spite of existing as a methodology in forensic science cheiloscopy has not been successfully utilized. The present study deals with the similarity of lip print patterns among parents and children. The total sample size consisted of 1399 individualsin the age group of 8-60 years belonging to Brahmins, Jats and Scheduled castes from Haryana and Delhi. Furthermore 8 monozygotic twin pairs were also taken in the present work. There persists resemblance among parents and children in their lip print patterns. But no significant association was found in the lip print patterns among twins. This can be an aid for narrowing down investigations, inclusions, exclusions and also a basis for genetic and inheritance implications.
\end{abstract}

\section{Introduction}

The characteristic patterns of the wrinkles and the grooves ( sulci labiorum) present on the labial mucosa constitutes the lip prints [1]. Cheiloscopy implies the study of these patterns. Forensic investigations dealing with personnel identification incorporates the applications of fingerprints, anthropology, odontology and other techniques like DNA profiling [2,3]. Recent advances in odontology have provided new dimensions in the field. In this genre cheiloscopy is a fast emerging and an effective tool. Lip prints aid as a tool in human identification due to its uniqueness and permanence [4]. The idea of using lip prints for personal identification was first exclaimed by Synder [5]. Suzuki and Tsuchihashi devised a classification system for lip prints and demonstrated that the lip print patterns are unique [6].

Various physical evidences like glass, cigarette butts, envelopes, cutlery items are the resources of latent lip prints. Lip prints from the crime scene are an aid to narrow down the investigation. Since it can provide basis for characterization with regard to inclusion, exclusion, gender, occupation, habits, cosmetic used, pathologies etc [7]. A range of chemical compositions from natural powder to lysochrome dyes have been explored to develop latent lip prints [8,9]. A breakthrough in the field is the use of luminescent reagents for developing aged prints [10].

Apart from individualization a wide array of studies reveal the untapped immense role of lip prints. The potential of lip prints to determine gender has been well exhibited [11-13]. Utsuna et al studied cadavers with various causes of death and their respective lip print characteristics [14] and subsequently investigated the postmortem changes in the lip impressions [14]. He further reported that eight corresponding features are mandatory for proving or disproving identity. Hirth et al explicated similarity of lip print patterns among siblings [15].

In spite of existing as a methodology in the field of forensics, an extensive data is lacking. A standardized and a cohesive approach is to be established. More researches should be done for building cohesive and a standardized system for lip print pattern examination and thus accomplish a complete utilization of the potential of lip prints.

In the present study heritability of lip prints has been investigated. Similarity of lip print patterns and heritability of anthropometric measurements of lips is assessed in parents and their offsprings. Furthermore, the study incorporates the determination of association of lip print patterns among twins.

\section{Material and Methods}

\section{Subjects}

The total sample size consisted of 1399 individuals comprising of 80 Brahmin families, 80 Jat families and 60 scheduled caste families from Delhi and Haryana each. Furthermore 8 monozygotic twin pairs were also taken in the present work. Informed consent was taken from each of them. The subjects were selected whose lips were free from any pathologies such as inflammation, mucosele, cicatrization and deformities such as cut marks or lesions.

\section{Recording the lip prints}

Dark colored, non persistent, non glossy, non metallic with less moisture and oil content lip sticks were used to develop clear lip prints. White papers (white A4 bilt Copy Power 75 gsm copy papers), transparent corporate's invisible cellulose tape and tissue papers (Kleenex) were used in the process. The strip of the tape was gently pressed from right side of subject's lips to the left end. It was taken care that during the process, the lips of the subject should be relaxed and slightly separated. The tape bearing the lip prints was then lifted and pasted on a white glaze paper sheet. The same technique has been used for both upper and lower lips. Care was taken that the tape covered the entire length and breadth of both the upper and the lower lip. Each print was recorded and kept in specific folders.

\section{Examination of the prints}

The obtained prints were analyzed using a magnifying lens since

*Corresponding author: Jasmine Kaur Dhall, Anthropology Department, University of Delhi, India, E-mail: jasmine_1759@yahoo.co.in

Received July 01, 2011; Accepted August 15, 2011; Published July 24, 2011

Citation: Vats Y, Dhall JK, Kapoor AK (2011) Heritability of Lip Print Patterns among North Indian Populations. J Forensic Res 2:137. doi:10.4172/2157-7145.1000137

Copyright: (c) 2011 Vats Y, et al. This is an open-access article distributed under the terms of the Creative Commons Attribution License, which permits unrestricted use, distribution, and reproduction in any medium, provided the original author and source are credited. 

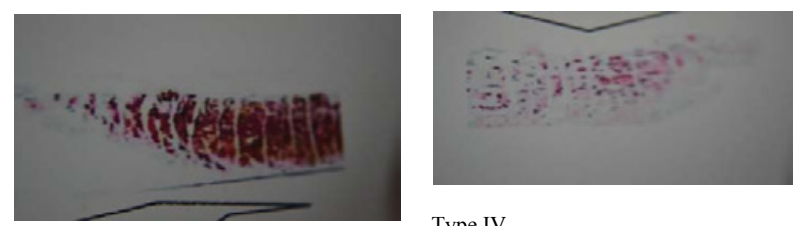

Type IV

Type I
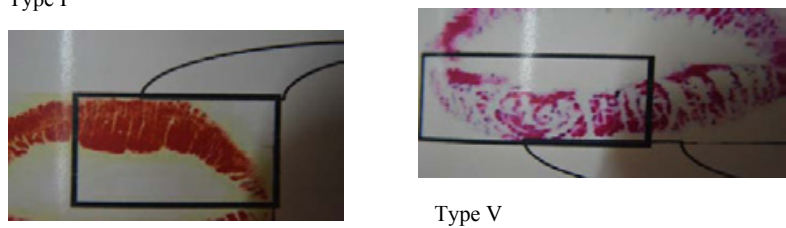

Type V

Type I'

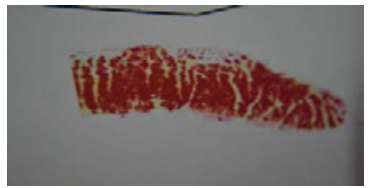

Type II

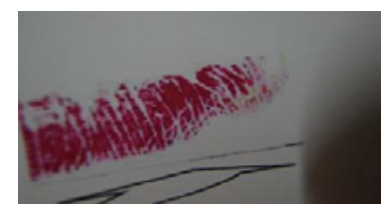

Type Y

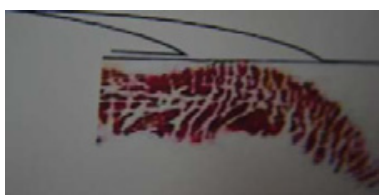

Type III

Figure 1: The various pattern types encountered in the population.

the lip print remains secured under the tape and can be analyzed even after two or more months of recording. The patterns were studied along the entire length and breadth of both the upper and the lower lip after dividing it into four equal quadrants (Figure 1). The lip prints were studied based on the classification of Suzuki and Tsuchihashi with modifications by including one more pattern type as encountered in the study [13]. Thus the used classification was as follows: I=long vertical grooves, $\mathrm{I}^{\prime}=$ short vertical grooves, $\mathrm{II}=$ branched grooves, III= diamond grooves, $\mathrm{IV}=$ rectangular grooves, $\mathrm{V}=$ unknown patterns, $\mathrm{Y}=$ blend of two or more than two patterns (Figure 1). The data was statistically analyzed.

\section{Statistical analysis}

All data was analyzed using SPSS statistical package version 17 to determine (1) percentage resemblance of lip prints among parents and their children, (2) association of lip print patterns among twins.

\section{Results and Discussion}

The lip print patterns observed in the three populations of the study are as follows

I=long vertical grooves, I'= short vertical grooves, $\mathrm{II}=$ branched grooves, $\mathrm{III}=$ diamond grooves, $\mathrm{IV}=$ rectangular grooves, $\mathrm{V}=$ unknown patterns, $\mathrm{Y}=$ blend of two or more than two patterns (Figure 1). Resemblance of lip print patterns is present on the four lip quadrants between father\& mother with their sons and daughters among Brahmins, Jats and Scheduled Castes of Delhi and Haryana as shown in Table 1.

Among the Brahmins, the percentage of resemblance among fathers and sons is maximum in the right lower quadrant $(36.93 \%)$ and minimum in the left upper quadrant. Likewise the maximum percentage of resemblance of father with daughter is in the left lower quadrant (26.25\%), which is less than the resemblance percentage of father with son. Between mother and offsprings, the percentage of resemblance (33.24\%) is maximum in the left upper quadrant in case of sons and it is (57.5\%) maximum in the left lower quadrant. The latter value is higher than the percentage resemblance between mother and son. The minimum resemblance is in the left lower quadrant among father-daughter, mother-son and mother -daughter.

Among the Jats, the percentage of resemblance of lip print patterns, among fathers and sons, fathers and daughters and mother and sons is maximum in the lower left quadrant $26.65 \%, 33.05 \%$ and $45.88 \%$ respectively. In contrast to these, the maximum percentage of resemblance among mothers and daughters is in the right upper quadrant $(46.43 \%)$. The minimum resemblance is in the left upper quadrant among all the four combinations.

Among the Scheduled Castes, the left lower quadrant exhibits the maximum percentage of resemblance among father-son (44.8\%), father-daughter (38.03\%) and mother -son $(35.06 \%)$ and minimum exhibited in the left upper quadrant among all the three. Antagonistically the maximum percentage of resemblance of the lip print patterns is in the left upper quadrant (43.16\%) and minimum in the right lower quadrant.

Among the three population groups, the maximum percentage of resemblance is shown by the Brahmin mothers and daughters in

\begin{tabular}{|c|c|c|c|c|c|c|c|c|c|c|c|c|c|c|c|c|c|c|c|c|c|c|c|c|}
\hline \multirow[b]{2}{*}{$\begin{array}{l}\text { Lip } \\
\text { Quadrants }\end{array}$} & \multicolumn{8}{|c|}{ Brahmins } & \multicolumn{8}{|c|}{ Jats } & \multicolumn{8}{|c|}{ Scheduled Castes } \\
\hline & RUS & LUS & $R L S$ & LLS & RUD & LUD & $R L D$ & LLD & RUS & LUS & $R L S$ & LLS & $R U D$ & LUD & $R L D$ & LLD & RUS & LUS & RLS & LLS & RUD & LUD & RLD & LLD \\
\hline RUF & 25.28 & & & & 16.25 & & & & 26.2 & & & & 19.64 & & & & 18.83 & & & & 20.94 & & & \\
\hline LUF & & 24.43 & & & & 27.5 & & & & 16.13 & & & & 18.75 & & & & 9.09 & & & & 9.4 & & \\
\hline$R L F$ & & & 36.93 & & & & 26.25 & & & & 32.72 & & & & 25.89 & & & & 42.86 & & & & 17.09 & \\
\hline LLF & & & & 27.55 & & & & 28.75 & & & & 26.65 & & & & 33.05 & & & & 44.8 & & & & 38.03 \\
\hline RUM & 20.74 & & & & 16.25 & & & & 41.07 & & & & 46.43 & & & & 21 & & & & 26.49 & & & \\
\hline LUM & & 33.24 & & & & 52.5 & & & & 38.79 & & & & 25.89 & & & & 13.64 & & & & 43.16 & & \\
\hline$R L M$ & & & 23.86 & & & & 55 & & & & 38.90 & & & & 27.68 & & & & 29.87 & & & & 18.8 & \\
\hline LLM & & & & 28.41 & & & & 57.5 & & & & 45.88 & & & & 33.93 & & & & 35.06 & & & & 41.88 \\
\hline
\end{tabular}

RUF, RUM, RUS and RUD-Right upper lip quadrant of father, mother, son and daughter respectively

LUF, LUM, LUS, LUD- Left upper lip quadrant of father, mother, son and daughter respectively

RLF, RLM, RLS, RLD-Right lower lip quadrant of father, mother, son and daughter respectively

LLF, LLM, LLS, LLD-Left lower lip quadrant of father, mother, son and daughter respectively

Table 1: Percentange resemblance of lip print patterns among parents and their children of Brahmins, Jats and Scheduled Castes from Delhi and Haryana. 
Citation: Vats Y, Dhall JK, Kapoor AK (2011) Heritability of Lip Print Patterns among North Indian Populations. J Forensic Res 2:137. doi:10.4172/21577145.1000137

Page 3 of 3

\begin{tabular}{|c|c|c|c|c|c|}
\hline Twins & Lip Quadrants & RU2 & LU2 & RL2 & LL2 \\
\hline M & RU1 & 0.155 & & & \\
\cline { 2 - 6 } A & LU1 & & 0.504 & & \\
\cline { 2 - 6 } E & RL1 & & & 0.392 & \\
\cline { 2 - 6 } & LL1 & & & & 0.329 \\
\hline F & RU1 & 0.223 & & & \\
E & LU1 & & 0.223 & & \\
M & RL1 & & & 0.223 & \\
\hline L & LL1 & & & & 0.383 \\
\hline
\end{tabular}

RU1 \& RU2- Right upper lip quadrant LU1 \& LU2- Left upper lip

Table2: Association of lip print patterns betweenfirst and second member of MZ twin pair.

the lower lip quadrant. The minimum exhibited by Scheduled Castes fathers and sons in the left upper quadrant (9.09\%).

The results dealing with the association of lip print patterns between first and second member of monozygotic twin pairs is shown in Table2. The significance of association is obtained using chi-square test. The ' $p$ ' values between male members with respect to the four quadrants are $0.155,0.504,0.392$ and 0.329 for right upper, left upper, right lower and left lower respectively. Similarly, between female pair, the value are $0.223,0.223,0.223$ and 0.383 respectively. All these values are non significant at $5 \%$ level of significance. Variation can be seen in monozygotic twins. The association shows that the lip print patterns are unique in monozygotic twins also. However, it cannot be concluded with certainity as the sample size is negligible to produce any significant result.

Certain other studies have shown similarities in the lip print patterns of children with their parents and among siblings [15]. This is not in concordance with some other studies which report no similarities [16].

\section{Conclusion}

In the recent years cheiloscopy has emerged as a pivotal tool for forensic investigations The present study depicted that there persists similarity of lip print patterns among parents and their offsprings but no association is found in lip print patterns of monozygotic twins. The lacuna is that inspite of the immense role, there have been only limited and akin studies done in the field. A detailed analysis of different aspects of lip prints should be done. Complete utilization of this evidence can be achieved by standardizing the methods and opining

the minimum matching points required, Extensive chemical methods and sophisticated software tools should be developed. Besides all this, the anthropological aspects of lip print patterns should be practiced, which can enable narrowing down of the investigation process.

\section{References}

1. Satyanarayna NK (2011) Forensic odontology: cheiloscopy. Hong Kong Dental Journal 8: 25-28.

2. Budowle B, Bieber FR, Eisenberg AJ (2005) Forensic aspects of mass disasters: strategic considerations for DNA- based human identification. Legal Medicine 4: 230-243.

3. Rai B, Anand SC (2007) Role of forensic odontology in tsunami disasters. The Internet Journal of Forensic Science 2: 1.

4. Tsuchihashi $Y$ (1974) Studies on personal identification by means of lip prints Forensic Science International 3: 233-248.

5. Snyder LM (1977) Homicide Investigation. (3rd Ed.). Charles C Thomas, Springfield.

6. Suzuki K \& Tsuchihashi $Y$ (1971) A new attempt of personal identification by means of lip print. Canadian Society of Forensic Science Journal 4: 154-158.

7. Reddy LVK (2011) Lip prints: An overview in Forensic Dentistry. Journal of Advanced Dental Research 2: 17-20.

8. Singh NN, Brave VR, Khanna S (2010) Natural dyes versus lysochrome dyes in cheiloscopy: A comparative evaluation. Journal of Forensic Dental Sciences 2: 11-17.

9. Kumar P, Mastan KMK, Patil S (2010) Cheiloscopy: Efficacy of Flouroscent dye over lysochrome dye in developing invisible lip prints. International Journal of Contemporary Dentistry 1: 3-6.

10. Castello A, Segui MA, Verdu FA (2005) Lumenous lip-prints as crimina evidence. Forensic Science International 155: 185-187.

11. Sharma P, Saxena S, Rathod V (2010) Cheiloscopy: the study of lip prints in sex identification. Journal of Forensic Dental Sciences 1: 24-27.

12. Gondivkar SM, Indurkar A, Degwekar S, Bhowate R (2009) Cheiloscopy for sex determination. Journal of Forensic Dental Sciences 1: 56-60.

13. Domiaty MAE, Al-gaidi SA, Elayat AA, Safwat MDE, Galal SA (2010) Morphological patterns of lip prints in Saudi Arabia at Almadinah Almonawarah province. Forensic Science International 200: 179.e1-179.e9.

14. Utsuno H, Kanoh T, Tadokoro O, Inoue K (2005) Prelimnary study of postmortem identification using lip prints. Forensic Science International 149: 129-132.

15. Hirth L, Gottsche H, Goedde HW (1977) Lip prints- variability and genetics. Human Evolution 8: 709-710.

16. Patel S, Paul I, Madhusudan AS, Ramesh G, Sowmya GV (2010) A study of lip prints in relation to gender, family and blood group. International Journal of Ora and Maxillofacial Pathology 1: 4-7. 